\title{
Left Hemihepatectomy
}

National Cancer Institute

\section{Source}

National Cancer Institute. Left Hemihepatectomy. NCI Thesaurus. Code C51571.

Surgical removal of the left hemisphere of the liver. 